\title{
COMMENT
}

\section{Invited Commentary on 'Prospective associations between television in the preschool bedroom and later bio-psycho-social} risks'

\author{
Aric Sigman ${ }^{1}$ \\ Pediatric Research (2019) 85:925-926; https://doi.org/10.1038/s41390-019-0357-0
}

\section{ERRING ON THE WRONG SIDE OF PRECAUTION}

Children's screen media habits are embedded early and last for decades and probably for life. By the time the average American child finishes their 8th year, they will have spent more than a full year of 24-h days on recreational screen time. Shaping their screen media habits in a positive direction from an early stage is therefore imperative.

At a time when discretionary (non-homework) screen time (DST) is the single main activity of First World children, medical bodies from WHO to the US, Australian and New Zealand Departments of Health to the American Academy of Pediatrics and Canadian Pediatric Society increasingly offer parents recommended DST limits as a sensible precautionary measure while research continues. The paper by Pagani et al. and the lead author's previous work reports 'developmental persistence in how youth invest their discretionary time' but adds a new dimension: screen location in early years predicts higher DST and significantly less favourable health and developmental outcomes years later and concludes that 'This research supports a strong stance for parental guidelines on availability and accessibility. ${ }^{2}$

Yet on the journey to societal awareness, these public health messages are often met with various calculated obstructions. Parents, including health professionals, are often informed about children and DST through mainstream media, social media, blogs and free online encyclopedias where the issue is often portrayed as an ongoing 'hotly debated' cultural issue reflecting a clash between generations, with accompanying headlines such as 'Screen Time: Is it good or bad for our kids?'.

The Times recently informed the British public that the 'mental health risk of screens' for teenagers is no greater than 'eating potatoes', explaining that medical concerns are based on 'cherrypicking of vague research that throws up spurious correlations'.

The New York Times Health section asks 'But surely screen addiction is somehow bad for the brain?' and immediately answers 'It's probably both bad and good for the brain', reassuring parents that because they watched hours of TV a day themselves as youngsters, 'their experiences may be more similar to their children's than they know'.

The BBC has just informed Britain 'Worry less about children's screen use, parents told. There is little evidence screen use for children is harmful in itself, guidance from leading paediatricians says'.

It is worth pointing out that, uniquely, information about the association between DST and paediatric health is increasingly controlled by and accessed through the very media being studied.
Screen media often presents itself as a mere neutral platform through which to access information; however, it is worth considering, for example, that BBC Worldwide generates \$1.4 billion in 'Headline' sales annually from its screen-based products and services. Furthermore, it is almost entirely unheard of for journalists or media to reveal that a DST health study being reported on in the news often emanates from an institution with significant funding from well-known screen media corporations including Google and Facebook.

There are more concerted overtures to influence public and professional perception of this health issue and prevent or discredit precautionary guidance. In 2017, a group of 81 predominantly British and American academic psychologists, including notable luminaries, were so 'deeply concerned' about the prospect of British Government health authorities merely offering loose precautionary guidance to parents on excessive child DST that they signed an open letter published in a national newspaper read by many doctors, urging Government doctors not to do so because it would be on the basis of 'little to no evidence' that 'risks'... 'potentially harmful policies'. Guidelines for parents should be 'built on evidence, not hyperbole and opinion'.

The Research Director of the Digital Media and Learning Hub, University of California, has attacked the APA's 'killjoy 'screen time' rules that had deprived countless kids', lamenting 'but damage has been done. ${ }^{\prime 3}$

Such debate and conflicting stories may be good for news and social media, drawing the eye to contrariness. However, this is undermining ongoing initiatives to raise awareness among parents that excessive DST is an evolving health issue and to encourage and support them in limiting their children's excess and late night use.

The purported justification for refraining from offering precautionary DST guidelines is a lack of evidence-based decisionmaking. Moreover, we are informed most of the evidence is correlational, some of the effect sizes are small, some findings are inconclusive, therefore precautionary guidelines are premature and unjustified.

This point of view appeals to our belief in the impartiality of science and preference for evidence-based decision-making, whereby any precautionary paediatric guidance is 'grounded in robust research evidence': systematic reviews of longitudinal randomised controlled studies.

We would all like to have the luxury of formulating public health guidance on the basis of comprehensive neatly quantified data

${ }^{1}$ All-Party Parliamentary Group on a Fit and Healthy Childhood, London, UK

Received: 4 February 2019 Accepted: 20 February 2019

Published online: 5 March 2019 
from prospective randomised controlled trials. And it is frustrating to find that the study of DST does not conform to that of other more established areas of paediatric public health.

However, this copious popular refrain 'evidence-based' reported in the media is an entirely disingenuous misappropriation of the entire concept of evidence-based medicine. When it comes to policy-making and guidance on child health, the established position remains 'an ounce of prevention is worth a pound of cure'. For example, WHO considers the precautionary principle 'a guiding principle... for $\mathrm{WHO}$ and everyone engaged in public health',

There are times in paediatric public health/preventive medicine when the luxury of 'robust research evidence' is not yet available. Moreover, as Pagani et al.'s study design makes clear, DST is obviously not a pharmaceutical substance but a complex, multifactorial lifestyle behaviour. ${ }^{2}$ Therefore, producing definitive proof of causation in the many domains of study, from neurobiology to psycho-social, will be a long time coming.

And this is where the calculated obstructions come in to play. As WHO observes, 'The precautionary principle is occasionally portrayed as contradicting the tenets of sound science and as being inconsistent with the norms of "evidence-based" decisionmaking... these critiques are often based on a misunderstanding of science and the precautionary principle... people must humbly acknowledge that science has limitations in dealing with the complexity of the real world... thus, there is no contradiction between pursuing scientific progress and taking precautionary action. $^{4}$

Positioning themselves as standard-bearers of high empiricism, those opposed to offering precautionary DST guidance have appropriated the term 'evidence-based' in an attempt to mislead society into thinking that to selectively highlight research findings of unfavourable associations between screen misuse and health outcomes and err on the side of the precautionary principle while research continues is a form of unprofessional 'cherrypicking' of the evidence. It implies an attempt at public deception through the intentional omission of unsupportive evidence. Misutilitising the term 'evidence-based' is a move to misportray those erring on the side of precaution as employing lower empirical standards, and to those unfamiliar with the precautionary principle and standard protocols in paediatric public health-the public and most media-this may seem a convincing exorcism of shoddy practice. It certainly makes for provocative, entertaining media.

This media carnival, in essence, leaves the AAP, the US, Australian and New Zealand Departments of Health, and WHO among others, along with the authors of many highly respected studies conducted at highly respected institutions published in highly reputable journals, as incompetent, untrustworthy and unprofessional. It wrongly casts them as ignoring the intellectual and social benefits of screen technology and preventing children from 'exploring the world around them' and developing their full potential. ${ }^{3}$

Such a position indicates either a profound misunderstanding or the intentional obfuscation of the relationship between science and the precautionary principle, and a high disregard for the experience and clinical judgement of child health professionals.

Those opposed to offering precautionary DST guidance have wilfully avoided the distinction between in-house empirical arguments between scientists versus the routine need to develop responsible general protective health guidance for children. They have misappropriated and emphasised the obvious limitations of existing research as a way of casting doubt on the entire public health issue and on the credibility of those simply advocating moderation and sensible precaution, in the hope that DST guidelines will be perceived as impetuous and premature scaremongering. We are urged to err on the wrong side of caution.

However, rigidly adhering to an abstract principle of high empiricism, with a distorted interpretation of evidence-based medicine taking precedence over the protection of children's health, should be considered self-indulgent and medically unethical. Furthermore, it reveals a high disregard for the important role of the experience and judgement of child health professionals to interpret available evidence, and promotes a hubristic picture of psychology and 'educational technology' researchers knowing better than the many paediatric and public health professionals what is best for protecting child health.

The burden of 'proof' must now be on them to demonstrate that high and/or premature exposure to DST-and now bedroom screens-pose no health and development risks to children. The time has come for health professionals to begin to scrutinise the motives of those attempting to obstruct provisional guidance on child DST. They are violating the precautionary principle. Fortunately, research teams such Pagani et al continue to uphold it by addressing the elephant in the room-the overlooked issue of how the mere location of a screen may potentiate greater DST and attenuate necessary developmental experiences. We should follow their advice.

\section{ADDITIONAL INFORMATION}

Competing interests: The author lectures at schools, medical schools and occasional parent groups on a range of child health education/public health subjects that occasionally include screen dependency disorders/discretionary screen time.

Publisher's note: Springer Nature remains neutral with regard to jurisdictional claims in published maps and institutional affiliations.

\section{REFERENCES}

1. Sigman, A. Screen dependency disorders: a new challenge for child neurology. J. Int. Child Neurol. Assoc. 17, 119-132 (2017).

2. Pagani, L. S., Harbec, M. J., \& Barnett, T. A. Prospective associations between television in the preschool bedroom and later bio-psycho-social risks. Pediatr. Res. (2018). https://doi.org/10.1038/s41390-018-0265-8. [EPub ahead of print].

3. Ito, M. How dropping screen time rules can fuel extraordinary learning. LSE Parenting for a Digital Future. http://blogs.Ise.ac.uk/parenting4digitalfuture/2017/06/ 21/how-dropping-screen-time-rules-can-fuel-extraordinary-learning/ (2017).

4. Martuzzi, M. \& Tickner, J. A. (eds). The Precautionary Principle: Protecting Public Health, the Environment and the Future of our Children (World Health Organization, Copenhagen, 2004). 